The Geneva Papers on Risk and Insurance, 20 (No. 76, July 1995) 269-273

\title{
Biotechnology for Insurers: Reflections and Suggestions*
}

\author{
by Mark F. Cantley**
}

\section{The "biological revolution" 1}

The scientific and technological wonders which constitute or underpin modern biotechnology can be summarised in three words: molecularisation, informatisation, globalisation. The last five decades, especially the last two, have seen dramatic and accelerating progress in our understanding of the structure and functioning of all living organisms. DNA is a data tape; a data tape that can be read (at a price) anywhere in the world. The price of reading it is falling, and the efforts devoted to understanding and modifying it are increasing. Across all the life science disciplines, and across all their areas of application, there is a surge of new information, available, or potentially available.

This information (or even its availability in principle) has pervasive effects, and subversive consequences. It is a common thread across diverse areas, including those of possible interest to the insurance industry. But the consequences differ widely from sector to sector, whether we speak of biotechnology or of insurance. Genetic screening or testing may produce information of special significance for individuals, their relatives, their medical advisers and their life insurance. Conjectures about health or environmental damage from the use of genetically modified plants or micro-organisms may be the basis for litigation, protest actions, and public liability insurance claims.

\section{Biotechnology should disappear (like the Cheshire cat)}

In spite of the fuss, there is a strong reason for expecting or arguing that biotechnology should disappear: should fade away, like the Cheshire cat in Lewis Carroll's novel, "Alice in Wonderland". For it is an inter-disciplinary activity, drawing upon established disciplines such as biochemistry, microbiology, process engineering, genetics and others. This activity

* Paper presented at the 5th International Conference of the Geneva Association on Strategic Issues in Insurance, London, October 26, 1994.

** Head of the Biotechnology Unit in the Directorate for Science, Technology and Industry, Organisation for Economic Co-operation and Development, Paris. Opinions expressed in this article engage only the author, and are not statements of OECD policy.

1 See, for example, "The Genetic Revolution: Scientific Prospects and Public Perceptions", ed. Bernard D. Davis, 1991; The Johns Hopkins University Press, Baltimore and London. 
has generated a surge of new knowledge and related techniques, which from initial discoveries and applications within basic biological research, are progressively being assimilated, and further developed and applied, within existing economic sectors.

The sectors of application of the life sciences are mainly three:

- the agro-food sector, encompassing the whole chain from agriculture/fishing/forestry, including their inputs, to the processing and transformation after the farm gate, into foods and other products;

- the health care and pharmaceuticals sector, including the products and services associated with prophylactics (vaccines), diagnosis and therapy;

- the environment sector, meaning all the diverse activities relating to the interface between man and nature: such as water purification; the treatment and recycling of organic wastes; the prevention, detection and remediation of environmental contamination; and the protection of the natural environment.

\section{OECD publications: from "generic" to "sectoral"}

The "disappearance" of biotechnology as a distinct issue, a distinct area of concern for government policy-makers, can be described as a progressive shift from "generic" to "sectoral" pre-occupations.

This shift of pre-occupations can be illustrated by the successive OECD publications on biotechnology-related matters. These publications are not simply the commercial judgement by a publishing-house of what will sell; each represents, rather, a political act of decision or consent by the 24 (since mid-94, 25) Member governments. Each publication is the outcome of expert study or extended working group meetings over a couple of years or longer, and represents a commitment of resources, sometimes on a considerable scale; particularly, the time of specialist experts.

1. (1982): "Biotechnology: International Trends and Perspectives", by A.T. Bull, G. Holt and M.D. Lilly.

2. (1985): "Biotechnology and Patent Protection: An International Review", by F. K. Bair, R. S. Crespi and J. Straus.

3. (1986): "Recombinant DNA Safety Considerations"

4. (1988): "Biotechnology and the Changing Role of Government".

5. (1989): "Biotechnology: Economic and Wider Impacts".

6. (1992): "Safety Considerations for Biotechnology, 1992".

7. (1993): "Preamble to Reports on Scientific Considerations pertaining to the Environmental Safety of the Scale-up of Organisms developed by Biotechnology".

8. (1992): "Biotechnology, Agriculture and Food".

9. (1993): "Safety Evaluation of Foods derived by Modern Biotechnology".

10. (1993): "Safety Considerations for Biotechnology: Scale-up of Crop Plants".

11. (1994): "Bacterial Mineral Leaching: a Summary with reference to the application of the bacteria".

12. (1994): "Aquatic Biotechnology and Food Safety". 
13. (1994): "Biotechnology for a Clean Environment".

14. (1995): "Safety Considerations for Biotechnology: Scale-up of Micro-organisms as Biofertilizers".

15. (1995): (co-published with IABS, the International Association of Biological Standardization) "Non-Target Effects of Live Vaccines", Proceedings of a workshop held in Langen, Germany, 3-5 November, 1993.

In this list, the first decade of reports were all "generic", addressing issues relating to recombinant DNA or biotechnology without sectoral specificity. From 1992 on, all the reports (except the general "Preamble", item 7) have had a specific focus, on one or other (or on sub-sectors of) the three application sectors cited.

\section{4. ...but the grin remains: stigmatisation, and regulatory consequences}

Lewis Carroll's Cheshire cat "vanished quite slowly, beginning with the end of the tail, and ending with the grin, which remained some time after the rest of it had gone".

With biotechnology, while the associated activities - economic, regulatory or whatever - may vanish as they are assimilated within sectoral activities, something may indeed "remain, some time after the rest of it had gone"; but the something is the hostile grin of stigmatisation. For a variety of reasons, some superficial, others reflecting deep cultural attitudes and value-laden sensitivities, biotechnology has troubled public opinion; and particularly in some countries of northern Europe, continues to be perceived as having high inherent risks. Details have been measured and documented in major and professionallyconducted public opinion surveys, such as those of "Eurobarometer" 2 in 1991 and 1993.

These perceptions, driven also by various "public interest" groups hostile to science and technology, or to "tampering with Nature", have amplified the drive towards biotechnology-specific regulations. The OECD 1986 "Blue Book" (item 3 in the list above) included the text of an OECD Council Recommendation adopted that year, and containing the agreed observation that

\section{"there is no scientific basis to justify specific legislation for recombinant DNA organisms".}

Nonetheless, national legislation of just such a nature was proposed and adopted, first in Denmark (1986), and in Germany - two countries having the highest risk perceptions of biotechnology in the European Union. Faced with this national fragmentation threatening the common market, the Commission proposed in 1988 Directives on the contained use (e.g. in research, and in industrial production) of genetically modified micro-organisms; and on the field release (e.g. in agriculture) of genetically modified organisms (e.g. plants, micro-organisms, animals). The Directives (90/219, and 90/220) were adopted in 1990, and are currently being implemented through national legislation, both in the Member countries of the European Union, and in the countries aspiring to membership, or at least wishing to have regulations compatible with those of the EU.

The US did not follow the European direction, but, consistently with the 1986 OECD Council Recommendation, has continued to treat regulatory oversight of biotechnology within existing statutory frameworks, relevant to the various sectors. Regulations have been

2 "Biotechnology and Genetic Engineering: What Europeans think about it in 1993". Survey conducted in the context of Eurobarometer 39.1 (results of the 1993 survey, with comparable figures from the 1991 survey). European Commission, DG XII. 
promulgated and modified, progressively diminishing in weight as time has gone on. In Japan, although DNA activities have been the focus of regulatory oversight, this has been achieved not by statute, but through "administrative guidelines" which are straightforward to adapt in the light of accumulating experience and knowledge, and have been so adapted.

Faced with the evolution of biotechnology regulations in their main competitors, with the absence of any evidence of dangers specific to biotechnology per se, and with a strongly increasing level of complaints from European industry ${ }^{3}$ and scientific circles ${ }^{4}$, the European Commission first in $1991^{5}$, and again in the December 1993 White Paper on "Growth, Competitiveness and Employment" 6 announced its intention to revise and simplify the regulatory frameworks for biotechnology. A further communication spelling out the details ${ }^{7}$ was presented at the European Council (the summit meeting of EU Prime Ministers) in June 1994. However, it is clear that the Commission proposals will face heavy opposition in the European Parliament, and from "Green" movements, who (at least in Europe) paradoxically continue to stigmatise genetic engineering and biotechnology, in spite of their obviously greater environment-friendliness than the less precise products and methods they displace. The stigmatisation remains, and its removal may be unwelcome to individuals and institutional structures whose activities depend upon it.

\section{Is biotechnology necessary?}

It is obvious already that the molecular genetic techniques of biotechnology are indispensable to progress in health care, across the whole range of prevention (through vaccines), diagnosis and therapy. In agriculture and food processing, regulatory and consumer acceptance issues may delay the inevitable; but in plant breeding it is clear that no competitive company can long ignore the molecular knowledge or the power and precision which it offers in pursuit of the usual aims of quality improvement and cost reduction. Regarding environmental protection and remediation, the immediate urgency is less; but with the expansion of human population and the continuing growth of economic activities, the new knowledge will eventually have to be pressed into service, to enhance the capabilities and performance of traditional techniques, particularly in regard to the shift towards sustainability, and reduction of unwanted side-effects.

The answer to the question, "Is biotechnology necessary? is therefore clearly affirmative, for all three sectors.

${ }^{3}$ See the series of publications from the Brussels-based "Senior Advisory Group Biotechnology", most recently (April '94), "Biotechnology Policy in the European Union: Prescriptions for Growth, Competitiveness and Employment: A Response to the Union's 1993 White Paper on Growth, Competitiveness and Employment", a response to (6). to $(6)$

${ }^{4}$ See for example, the June 1994 statement of the European Science Foundation, in response

5 "Promoting the Competitive Environment for the Industrial Activities Based on Biotechnology within the Community", Commission of the European Communities, April 1991 (SEC (91) 629).

${ }_{6}^{6}$ "Growth, Competitiveness and Employment: The Challenges and Ways Forward into the 21st Century" (the "Delors White Paper"), European Commission, December 1993, COM (93) 700.

7 "Biotechnology and the White Paper on Growth, Competitiveness and Employment: Preparing the Next Stage", European Commission, June 1994. 


\section{Stigmatisation, insurability and regulation}

The stigmatisation of biotechnology is persistent, and the diffusion of rational regulatory practice from early US experience to Europe and elsewhere has been slow and troubled. Even as the European Union seeks to correct its earlier mistakes and excesses, there is pressure to repeat them in Eastern Europe and at global level. Old arguments about uncertainties and conjectural risks re-surface in UN agencies, and particularly in the context of the Rio "Earth Summit" and two of its results: "Agenda 21" (the 40-chapter action agenda for "sustainable development by the 21 st century"), and the Convention on Biological Diversity, whose Article 19.3 commits the signatory Parties to "consider the need for and modalities of a protocol setting out appropriate procedures, including, in particular, advance informed agreement, in the field of safe transfer, handling and use of any living modified organisms resulting from biotechnology that may have adverse effect on the sustainable conservation and use of biological diversity".

The language, in its detail, is cautious; but the impression conveyed is of stigmatisation (contrary to the evidence - for a competent review see Giddings and Persley ${ }^{8}$ ).

Similarly the Council of Europe, in March 1993, included "the use of genetically modified organisms or micro-organisms" under the scope of "dangerous activity" in the context of the European Convention on Civil Liability for Damage Resulting from Activities Dangerous to the Environment. The final text requires that each signatory state

"shall ensure that, where appropriate, taking account of the risks of the activity, operators conducting a dangerous activity on its territory be required to participate in a financial security scheme or to have and maintain a financial guarantee up to a certain limit, of such type and terms as specified by internal law, to cover the liability under this Convention."

Thus although the economic, scientific and technological logic may argue for the "disappearance" of biotechnology, and of biotechnology-specific regulation, it is clear that in at least some countries and international fora, earlier assumptions, perceptions and arguments will be persistent, pervasive and influential. These considerations must be recognised by the insurance industry, whose liability payments at the end of the day will not be entirely determined by objective expert argument, but by the choices of legislators and by the beliefs and prejudices of court-room juries and judges.

The insurance industry, in Europe and elsewhere, should at least be cognisant of the reasons for differences in regulatory philosophies; and recognise that weight of regulation is not a reliable indicator of severity of risk. Rather, such regulations address public opinion, it being argued that they are essential to public confidence in, and acceptance of, biotechnology; an argument analogous to saying that such regulations are needed, not primarily to protect the public from biotechnology, but to protect biotechnology from the public.

8 "Biotechnology and Biodiversity", a study prepared for the United Nations Environmental Programme (UNEP) by L. Val Giddings and G. Persley, for the Sub-Working Group on Biotechnology of the Ad Hoc Working Group of Experts on Biological Diversity, UNEP/Bio.Div/SWGB.1/3, 12 October 1990. 